\title{
International Registration of Cultivar Names for Unassigned Woody Genera: July 2004-June 2005
}

\author{
Mark C. Tebbitt \\ Registrar for Unassigned Woody Genera, Horticultural Taxonomist, Brooklyn Botanic Garden, 1000, Washington \\ Avenue, Brooklyn, NY 11225-1099
}

From July 2004 to June 2005, six cultivar names in unassigned woody genera were registered. Individuals introducing new cultivars of ornamental plants are encouraged to register these names with a view to nomenclatural stabilization. A directory of International Cultivar Registration Authorities and list of the unassigned woody genera is available at http://www.ishs.org/sci/iradirec.htm and from the American Association of Botanical Gardens and Arboreta, 100 West 10th Street, Suite 614, Wilmington, DE 19801 (http://www. aabga.org). All previously registered cultivars of unassigned woody genera are listed at https://www.bbg.org/sci/taxonomy/registration. html. The present International Cultivar Registration Authority for unassigned woody ornamentals can be contacted at the address above.

Acer shirasawanum 'Minori-no-tsuki'. Registered 31 May 2004. Registrant: Carl Munn, Munn's Nursery Inc., 9445 72nd Ave. N.E. Brooks, OR 97305-9754. Acer shirasawanum 'Minori-no-tsuki' originated as a chance seedling of Acer shirasawanum 'Aureum'. The cultivar name 'Minori-no-tsuki', translated from Japanese, means harvest moon and refers to the cultivar's golden toned fall foliage. The new cultivar is distinguished by the striking color contrast between its emerging, developing, and mature foliage. As the foliage emerges it is red, afterwards turning yellow, and then finally becoming green. The cultivar is also relatively hardy and resistant to sun scorch. A detailed description of Acer shirasawanum 'Minori-no-tsuki' appears on p. 2 of volume 13/3 of The Maple Society Newsletter. The cultivar is propagated via side grafts and is not yet available commercially.

Acer tataricum subsp. ginnala 'Ruby Slippers'. Registered 2 Sept. 2004. Registrant: Andrea Bonville, Princeton Nurseries, P.O. Box 185, Allentown, N.J. 08501. Acer tataricum subsp. ginnala 'Ruby Slippers' originated as a chance seedling in cultivation and was first propagated in 1991. This cultivar forms a small, compact tree with a particularly straight trunk. It produces distinctive scarlet samaras in June, which retain their color 2 weeks longer than those of the species and its cultivar 'Flame'. Its fall color is an attractive mix of orange, yellow, and red. This new cultivar has been available commercially from Princeton Nurseries since 2004. Photographs of the new cultivar have been deposited at the Herbarium of Brooklyn Botanic Garden.

Cornus kousa var. chinensis 'Wisley Queen'. Registered 1 Aug. 2004. Registrant: Mike Grant, Botany Department, R.H.S. Garden, Wisley, Woking, Surrey, GU23 6QB, U.K. Cornus kousa var. chinensis 'Wisley Queen' was selected in 2002 for its ability to form a tree, its reliable, upright habit and its broad bracts developing a pink flush. This tree is broadly vase shaped and reaches about $9 \mathrm{~m}$ in height at maturity. It has leaves that are broadly elliptic, with 4 (5) pairs of veins, and measure about $90 \times 55 \mathrm{~mm}$. Flowers are produced in June and have four overlapping floral bracts that are initially white, but later become splashed and ultimately heavily flushed with pinkishred. The bracts are orbicular, shortly apiculate, and measure 35 to
$43 \times 35$ to $48 \mathrm{~mm}$. This new cultivar is commercially available and a nomenclatural standard has been deposited at the Herbarium of the Royal Horticultural Society (WSY; barcode WSY0043668).

Fothergilla major 'Blue Shadow'. Registered 10 Nov. 2004. Registrant Gary Handy, Handy Nursery Co., 10702 S.E. McCreary Lane, Boring, OR 97009. Fothergilla major 'Blue Shadow' was selected in 2000 from a sport of Fothergilla major 'Mount Airy'. This new cultivar differs from that cultivar in having an intense blue-gray foliage color. It differs from Fothergilla gardeni 'Blue Mist', which also has blue foliage, by being more vigorous and by exhibiting greater heat and cold tolerance. The name Fothergilla major 'Blue Shadow' has been patented (U.S. Patent PP15,490). The cultivar is available commercially and a description of this plant has been published in North American Plants' 2004 catalogue. A photograph of the new cultivar has been deposited in Brooklyn Botanic Garden's herbarium.

Hippophae rhamnoides ssp. mongolica 'Harvest Moon'. Registered 12 Oct. 2004. Registrant: Bill Schroeder, AAFC-PFRA Shelterbelt Centre, Indian Head, SK, Canada S0G 2K0. Hippophae rhamnoides ssp. mongolicai 'Harvest Moon' was selected in 2000 as a chance seedling in cultivation. This new cultivar differs from most other similar cultivars in having particularly large fruit and relatively few soft thorns. It differs from Hippophae rhamnoides ssp. mongolicai 'Golden September' in the following ways: average berry weight is 0.7 to $0.8 \mathrm{~g}$, pedicel length is 5 to $6 \mathrm{~mm}$, and the fruit is sour sweet with a soluble sugar content of 11 to $12{ }^{\circ} \mathrm{Brix}$, a vitamin $\mathrm{C}$ content of 175 to $200 \mathrm{mg} / 100 \mathrm{~g}$, and a seed oil content of $11.0 \%$ to $12.0 \%$. The fruit are produced abundantly and readily harvested by hand or by shaking. At maturity the cultivar forms a compact shrub with a spread of $2 \mathrm{~m}$ and is easily trained into a single stem. The cultivar was first introduced commercially in 2005 via Canadian Prairies. It is hardy to zone 2a (Canada Plant Hardiness zones) and is adapted to well drained, medium textured soils.

Hippophae rhamnoides ssp. mongolica 'Orange September'. Registered 12 Oct. 2004. Registrant: Bill Schroeder, AAFC-PFRA Shelterbelt Centre, Indian Head, SK, Canada S0G 2K0. Hippophae rhamnoides ssp. mongolicai 'Golden September' was selected in 2000 as a chance seedling in cultivation. This new cultivar differs from most other similar cultivars in having above average fruit size and relatively few thorns. It differs from Hippophae rhamnoides ssp. mongolicai 'Harvest Moon' in the following ways: average berry weight is 0.5 to $0.6 \mathrm{~g}$, pedicel length is 3 to $4 \mathrm{~mm}$, and the fruit has a sugar content of 13 to $14^{\circ} \mathrm{Brix}$, a vitamin C content of 180 to 200 $\mathrm{mg} / 100 \mathrm{~g}$, and a seed oil content of $10.0 \%$ to $11.0 \%$. The average pulp oil content is 1.9 percent. The fruit are produced abundantly and readily harvested by hand or by shaking. At maturity the cultivar forms a medium shrub with a spread of $2 \mathrm{~m}$. The cultivar was first introduced commercially in 2005 via Canadian Prairies. It is hardy to zone 2a (Canada Plant Hardiness zones) and is adapted to well drained, medium textured soils. 